\title{
Dealing with air pollution in Europe
}

\author{
C. Trozzi, R. Vaccaro \& C. Leonardi \\ Techne Consulting srl, Via G. Ricci Curbastro, 3400149 Roma, Italy
}

\begin{abstract}
Air pollution in Europe is managed and controlled through the implementation of International Conventions, dealing with global issues such as climate change, transboundary pollution and stratospheric ozone and ensuring compliance with European Legislation, regulating ambient air quality and emissions from stationary and mobile sources.

In this paper a complete description of the main provisions which represent the reference legislative framework for this sector is given. Keywords: air pollution, legislation, European Union, LRTAP, UNFCC.
\end{abstract}

\section{Introduction}

Air pollution issues cover different geographical scales: from the local level, such as the sorroundings of isolated sources or urban locations to the global one, connected to all those phenomenon which invest wider areas. For this reason air quality management requests political strategies to be carried out and implemented at local, national and international level.

In Europe air pollution is managed and controlled through the implementation of International Conventions, dealing with global issues such as climate change, transboundary pollution and stratospheric ozone depletion and ensuring compliance with European Legislation, regulating ambient air quality and emissions from stationary and mobile sources.

In the following paragraphs a description of the main provisions which represent the reference legislative framework for this sector is given.

\section{International conventions}

\subsection{United Nations Framework Convention on Climate Change}

The United Nations Framework Convention on Climate Change (UNFCCC) came into force on March the $21^{\text {st }} 1994$ and represents a starting point to 
consider what can be done to reduce global warming and to cope with temperature increases [1]. Afterwards, governments agreed to an addition to the treaty, the Kyoto Protocol [2] that came into force on February the $16^{\text {th }} 2005$ and was approved by the European Community with Council Decision 2002/358/EC [3]. It shares the objective of the Convention and commits developed Countries to stabilize Green House Gas (GHG) emissions, with more powerful and legally binding measures.

The Protocol provides for three "flexibility mechanisms" that enable Annex I Parties to access cost-effective opportunities to reduce emissions, or to remove carbon from the atmosphere, in other Countries. The flexibility mechanisms are:

- the "Clean Development Mechanism" (CDM) provides for so called Annex I Parties to implement projects that reduce emissions in nonAnnex I Parties, or absorb carbon through afforestation or reforestation activities, in return for certified emission reductions;

- the "Joint Implementation" (JI) provides for Annex I Parties to implement an emission-reducing project or a project that enhances removals by sinks in the territory of another Annex I Party;

- "Emissions trading" provides for Annex I Parties to acquire units from other Annex I Parties (Directive 2003/87/EC establishing a scheme for GHG emission allowance trading within the Community and amending Council Directive 96/61/EC).

The Intergovernmental Panel on Climate Change (IPCC) produced specific Guidelines for National GHG Inventories, used for estimating anthropogenic emissions by sources and removals by sinks of GHG and for calculating legallybinding targets during the first commitment period.

The last 2006 IPCC Guidelines [4] take into account also the related Good Practice reports. The new guidelines cover new sources and gases and update methods where technical and scientific knowledge have been improved. In particular, default values of the various parameters and emission factors required are supplied for all sectors. The guidance also integrates and improves earlier guidance on good practice in inventory compilation so that the final estimates are neither over- nor under-estimates as far as can be judged and uncertainties are reduced as far as possible.

Council Decision 93/389/EEC [5], as amended by Decision 99/296/EC [6], establishes a monitoring mechanism of Community $\mathrm{CO}_{2}$ and other $\mathrm{GHG}$ emissions to help monitoring progress towards stabilisation of the total $\mathrm{CO}_{2}$ emissions by 2000 at the 1990 level in the Community as a whole. European Union committed to a reduction of the emissions of the six Kyoto Protocol gases (carbon dioxide, methane, nitrous oxide, perfluorocarbons, hydrofluorocarbons and sulphur hexafluoride) by 8\% in 2008-2012 from 1990 levels. Each year Member States shall report to the Commission on their anthropogenic emissions and removal by sinks for the previous calendar year and, on the most recent projected emissions for the period 2008-2012 and, as far as possible, for 2005. 


\subsection{Stratospheric ozone depletion}

In 1985, scientific concerns about damage to the ozone layer prompted Governments to adopt the Vienna Convention on the Protection of the Ozone Layer [7], which established an international legal framework for action. Two years later, in 1987, legally binding commitments were adopted through the Montreal Protocol on Substances that Deplete the Ozone Layer [8], which required industrialized Countries to reduce their consumption of chemicals harming the ozone layer. Additional requirements have been added to the Montreal Protocol through amendments adopted in London (1990), Copenhagen (1992), Montreal (1997) and Beijing (1999).

As of November 2007, 191 Countries have ratified the Montreal Protocol, which sets out the time schedule to "freeze" and reduce consumption of ozone depleting substances (ODS). The Protocol requires all Parties to ban exports and imports of controlled substances to and from non-Parties.

Production and consumption of CFCs, halons and other ozone depleting chemicals have been phased out in industrialized Countries and a schedule is in place to eliminate the use of methyl bromide, a pesticide and agricultural fumigant. Developing Countries (Article 5 Parties) operate under different phase-out schedules, having been given a grace period before phase-out measures would apply to them, in recognition of their need for industrial development and their relatively small production and use of ODS. They have agreed to freeze most CFC consumption as of 1 July 1999 based on 1995-97 averages, to reduce this consumption by $50 \%$ by January the $1^{\text {st }} 2005$ and to fully eliminate these CFCs by January the $1^{\text {st }} 2010$. Other control measures apply to ODS such as halons, carbon tetrachloride and methyl chloroform. For methyl bromide, used primarily as a fumigant, developed Countries froze their consumption at 1995 levels and will eliminate all use by 2010, while developing Countries have committed to freeze consumption by 2002 based on average 1995-98 consumption levels.

\subsection{Convention on Long-range Transboundary Air Pollution}

The Convention on Long-range Transboundary Air Pollution [9] is one of the central means for protecting our environment.

In November 1979 the Convention, which now has 51 Parties, was signed by 34 Governments and the European Community. It was the first international legally binding instrument to deal with problems of air pollution on a broad regional basis. The Convention entered into force in 1983 and has been extended by eight specific protocols, among which the first one (on EMEP Programme) and the last three (on heavy metals, POPs and acidification, eutrophication and ground-level ozone) are still in force:

1984 Protocol on Long-term Financing of the Cooperative Programme for Monitoring and Evaluation of the Long-range Transmission of Air Pollutants in Europe (EMEP); 42 Parties. Entered into force on January the $28^{\text {th }} 1988$ [10] It is an instrument for international cost-sharing of a monitoring programme based on three elements: collection of emission 
data for $\mathrm{SO}_{2}, \mathrm{NO}_{\mathrm{x}}$, VOCs and other air pollutants; measurement of air and precipitation quality; modelling of atmospheric dispersion.

1998 Protocol on Heavy Metals; 29 Parties. Entered into force on December the $29^{\text {th }} 2003$ [11]. It deals with three particularly harmful metals: cadmium, lead and mercury. Parties have to reduce their emissions below their levels in 1990 (or an alternative year between 1985 and 1995), cutting emissions from industrial sources, combustion processes and waste incineration. It lays down stringent limit values for emissions from stationary sources and suggests best available techniques (BAT). The Protocol requires Parties to phase out leaded petrol. It also introduces measures to lower heavy metal emissions from other products, and proposes the introduction of management measures for other mercurycontaining products, such as electrical components, measuring devices fluorescent lamps, dental amalgam, pesticides and paint.

1998 Protocol on Persistent Organic Pollutants (POPs); 29 Parties. Entered into force on October the $23^{\text {rd }} 2003$ [12]. It deals with 16 substances, comprising eleven pesticides, two industrial chemicals and three byproducts/contaminants. The ultimate objective is to eliminate any discharges, emissions and losses of POPs. The Protocol bans the production and use of some products outright (aldrin, chlordane, chlordecone, dieldrin, endrin, hexabromobiphenyl, mirex and toxaphene). Others are scheduled for elimination at a later stage (DDT, heptachlor, hexaclorobenzene, PCBs). Finally, the Protocol severely restricts the use of DDT, HCH (including lindane) and PCBs. The Protocol includes provisions for dealing with the wastes of products that will be banned. It also obliges Parties to reduce their emissions of dioxins, furans, PAHs and HCB below their levels in 1990 (or an alternative year between 1985 and 1995). For the incineration of municipal, hazardous and medical waste, it lays down specific limit values.

1999 Protocol to Abate Acidification, Eutrophication and Ground-level Ozone; 24 Parties. Entered into force on $17^{\text {th }}$ May 2005 [13]. The Protocol sets emission ceilings for 2010 for four pollutants: sulphur, $\mathrm{NO}_{\mathrm{x}}, \mathrm{VOCs}$ and ammonia. Parties whose emissions have a more severe environmental or health impact and whose emissions are relatively cheap to reduce have to make the biggest cuts. Once the Protocol is fully implemented, Europe's sulphur emissions should be cut by at least $63 \%$, its $\mathrm{NO}_{\mathrm{x}}$ emissions by $41 \%$, its VOC emissions by $40 \%$ and its ammonia emissions by $17 \%$ compared to 1990 . The Protocol also sets tight limit values for specific emission sources and requires BAT to be used to keep emissions down. VOC emissions from such products as paints or aerosols will also have to be cut. Finally, farmers will have to take specific measures to control ammonia emissions. Guidance documents adopted together with the Protocol provide a wide range of abatement techniques and economic instruments for the reduction of emissions in the relevant sectors, including transport. 


\subsection{European Union legislation}

\subsubsection{Ambient air quality}

The European Union legislation on ambient air quality and mainly the Framework Directive 96/62/CE [14] and the implementing provisions provided by the related four "Daughter" Directives [15-18], define the legislative basis for assessment and management of air quality in Member States.

The general aim is to define the basic principles of a common strategy to: define and establish objectives for ambient air quality in order to avoid, prevent

or reduce harmful effects on human health and the environment, assess ambient air quality on the basis of common methods and criteria, obtain adequate information on ambient air quality and ensure that it is made available to the public, maintain ambient air quality where it is good and improve it in other cases.

According to legislation, air quality assessment can be done through measurements and any other techniques of estimation, including modelling; the Framework Directive defines that assessment "shall mean any method used to measure, calculate, predict or estimate the level of a pollutant..."

For this reason, Daughter Directives introduce assessments thresholds for each pollutant, that are to be used to establish where measurements are mandatory and where other techniques can be used, in particular they set:

- Upper assessment thresholds, below which a combination of measurements and modelling techniques may be used to assess ambient-air quality;

- Lower assessment thresholds, below which only modelling or objectiveestimation techniques may be used.

When concentrations are over the upper assessment thresholds, measurements are mandatory and can be supplemented by other techniques.

Limit values, target values, long term objectives, alert and information thresholds are set in order to protect human health and the environment and specific provisions are established for air quality management through the implementation of plans to reduce concentrations of pollutants and obtain the best ambient air quality.

As one of the key measures outlined in the 2005 Thematic Strategy on air pollution, the new Air Quality Directive 2008/50/EC [19] has been recently adopted. It has the aim to simplify environmental legislation and in fact it merges in only one text the contents of the Framework Directive, the first three Daughter Directives and the Council Decision establishing a reciprocal exchange of information (EoI) and data from networks and individual stations measuring ambient air pollution within the Member States (Decision 97/101/EC, as amended by Decision 2001/752/EC) [20,21].

The new Directive doesn't change the existing air quality standards and the main contents of the previous legislative body but introduces some little changes about assessment criteria, natural contributions to pollutant levels and exemptions/derogations to the compliance to the limit values in particular conditions. Taking into account that it is now generally accepted that the fine fraction of particulate matter is the most dangerous for human health because it 
can lodge deeply in the lungs, really new provisions are those introduced about $\mathrm{PM}_{2,5}$ monitoring and control. In this case a threshold below which no significant risks for human health appear has not yet been identified and for this reason $\mathrm{PM}_{2,5}$ is to be controlled but not in the same way as other pollutants. In the new air quality Directive a double approach for this pollutant has been chosen.

The first one is aimed to reach a general reduction of concentrations in urban background locations, where the most part of population is likely to be exposed. This objective is pursued monitoring $\mathrm{PM}_{2,5}$ in Urban Background locations sited in agglomerations and urban areas with more then 100.000 inhabitants; concentrations are assessed as an average value over 3 years. During the period 2010-2020 a reduction of the exposition has to be reached, as far as possible; starting from 2015, an exposure concentration obligation of $20 \mu \mathrm{g} / \mathrm{m}^{3}$ is to be met and so the standard becomes mandatory.

The second approach is aimed to ensure a minimum degree of health protection everywhere, through establishing a target value $\left(25 \mu \mathrm{g} / \mathrm{m}^{3}\right)$ by 2010 and a limit value $\left(25 \mu \mathrm{g} / \mathrm{m}^{3}\right)$ by 2015 .

\subsubsection{Emissions}

\subsubsection{European Union Integrated Pollution Prevention and Control}

(IPPC) Directive Directive 2008/1/EC [22] is the codified version of the Directive 96/61/EC on Integrated Pollution Prevention and Control (IPPC) [23], that sets common rules on permitting for industrial installations; it merges in a single text all the previous amendments and introduces some linguistic changes and adaptations.

The Directive also provides that "an inventory of the principal emissions and sources responsible shall be published every three years by the Commission on the basis of the data supplied by the Member". The Commission Decision of 17 July 2000 on the implementation of a European Pollutant Emission Register (EPER) [24] requires Member States to report the Commission on emissions to air and water from all individual facilities with one or more activities for which "threshold values" are exceeded; both activities, pollutants and threshold values are specified in the Decision.

The Directive concern activities selected in the following sectors: energy industries, production and processing of metals, mineral industry, chemical industry, waste management, other activities (pulp; paper and board; fibers or textiles; tanning of hides and skins; slaughterhouses; animal and vegetable food products; milk; disposal or recycling of animal carcasses and animal waste; intensive rearing of poultry or pigs; surface treatment using organic solvents in particular for dressing, printing, coating, degreasing, waterproofing, sizing, painting, cleaning or impregnating; carbon (hard-burnt coal) or electro graphite by means of incineration or graphitization).

\subsection{Other directives on stationary sources}

- Directive 2001/80/EC on the limitation of emissions of certain pollutants into the air from Large Combustion Plants (LCP) [25], is aimed to reduce 
emissions of acidifying pollutants, particles, and ozone precursors from LCPs, that are those whose rated thermal input is equal to or greater then 50 MW. The Directive establishes specific provisions for existing and new plants and provides for emission limit values for $\mathrm{SO}_{2}, \mathrm{NO}_{\mathrm{x}}$ and dust. For existing plants, Member States can also implement a National reduction plan to achieve overall reductions calculated using the emission limit values or a combined approach (limit values and plan).

- Directive 2000/76/EC on Waste Incineration [26], is aimed to prevent or reduce as far as possible negative effects on the environment (air, soil, surface water and groundwater) caused by the incineration and coincineration of waste, through the application of operational conditions, technical requirements, and emission limit values for waste incineration and co-incineration plants.

- Directive 1999/13/EC, on the limitation of emissions of volatile organics compounds (VOC) due to the use of organic solvents in certain activities and installations [27], covers emissions of organic solvents from stationary, commercial and industrial sources by setting emission limits for such compounds and laying down operating conditions for industrial installations;

- Directive 2004/42/EC on the limitation of emissions of VOC due to the use of organic solvents in decorative paints and varnishes and vehicle refinishing products (Decopaint, amending Directive 1999/13/EC) [28].

\subsubsection{Fuel quality}

The subject is regulated by Council Directive 1999/32/EC relating to a reduction in the sulphur content of certain liquid fuels [29]; it is aimed to reduce the emissions of sulphur dioxide resulting from the combustion of certain petroleum-derived liquid fuels and thereby to reduce the harmful effects of such emissions on man and the environment. Such reductions shall be achieved by imposing limits on the sulphur content of such fuels as a condition for their use. The issue is also covered by Directive 2005/33/EC as regards the sulphur content of marine fuels [30].

European legislation also establishes some provisions about quality of fuels used for vehicles in order to reduce pollution coming from car emissions: a ban on the marketing of leaded petrol and an obligation to make sulphur-free fuels available within the Union.

The main Directives in this case is Directive 98/70/EC relating to the quality of petrol and diesel fuels [31] with the following amendments contained in Directive 2000/71/EC [32] and Directive 2003/17/EC [33].

\subsubsection{Mobile sources}

Further reductions on pollutants emissions are also obtained through regulations about Mobile sources. EU established emission standards for different kind of vehicles. In particular, for light-duty vehicles (cars and light vans) the emission standard currently in force is Euro 4, as defined by Directive 98/69/EC [34]. New Euro 5 and Euro 6 standards have already been agreed by Council and Parliament and formally adopted by the Council in 2007. The implementing 
legislation is currently under preparation. Euro 5 will enter into force in September 2009 while Euro 6 is scheduled to enter into force in January 2014.

For heavy-duty vehicles (trucks and buses), Directive 2005/55/EC [35] and Directive 2005/78/EC [36] define the emission standard currently in force, Euro IV, as well as the next stage (Euro V), which will enter into force in October 2008. In addition, a non-binding standard called Enhanced Environmentallyfriendly Vehicle (EEV) is introduced; the Commission has also made a proposal for a new Euro VI stage in December 2007.

\section{References}

[1] United Nations, Framework Convention on Climate Change, 1992

[2] United Nations Framework Convention on Climate Change, Kyoto Protocol to the United Nations Framework Convention on Climate Change, Report of the Conference of the Parties on its third session, held at Kyoto from 1 to 11 December 1997, FCCC/CP/1997/7/Add., 18 March 1998

[3] Council Decision 2002/358/EC of 25 April 2002 concerning the approval, on behalf of the European Community, of the Kyoto Protocol to the United Nations Framework Convention on Climate Change and the joint fulfilment of commitments thereunder, Off. Jour. Europ. Comm. L 130, 15.5.2002, p. $1-3$

[4] 2006 IPCC Guidelines for National Greenhouse Gas Inventories, Prepared by the National Greenhouse Gas Inventories Programme, Eggleston H.S., Buendia L., Miwa K., Ngara T. and Tanabe K. (eds), IGES, Japan.

[5] Council European Union Decision 93/389/EEC of 24 June 1993 for a monitoring mechanism of Community $\mathrm{CO}_{2}$ and other greenhouse gas emissions, Off. Jour. Europ. Comm. L 167, 09.07.1993 p. 31

[6] Council European Union Decision 1999/296/EC of 26 April 1999 amending Decision 93/389/EEC for a monitoring mechanism of Community $\mathrm{CO} 2$ and other greenhouse gas emissions, Off. Jour. Europ. Comm. L 117, 05.05.1999 p. 35

[7] United Nations Environment Programme - Ozone Secretariat, The Vienna Convention for the Protection of the Ozone Layer, Secretariat for the Vienna Convention for the Protection of the Ozone Layer \& The Montreal Protocol on Substances that Deplete the Ozone Layer, 2001

[8] United Nations Environment Programme - Ozone Secretariat, The Montreal Protocol on Substances that Deplete the Ozone Layer as adjusted and/or amended in London 1990, Copenhagen 1992, Vienna 1995, Montreal 1997, Beijing 1999, Secretariat for The Vienna Convention for the Protection of the Ozone Layer \& The Montreal Protocol on Substances that Deplete the Ozone Layer, 2000

[9] Convention on long-range transboundary air pollution (CLRTAP), Geneva, 1979

[10] Protocol to the 1979 "Convention on long-range transboundary air pollution" on long-term financing of the cooperative programme for 
monitoring and evaluation of the long-range transmission of air pollutants in Europe (EMEP), Geneva, 1984

[11] Protocol to the 1979 "Convention on long-range transboundary air pollution" on Heavy Metals, Aarhus, 1998

[12] Protocol to the 1979 "Convention on long-range transboundary air pollution", on Persistent Organic Pollutants (POPs), Aarhus, 1998

[13] Protocol to the 1979 "Convention on long-range transboundary air pollution" to abate acidification, eutrophication and ground-level ozone, Gothenburg, 1999

[14] Council European Union, Directive 1996/62/EC of 27 September 1996 on ambient air quality assessment and management, Off. Jour. Europ. Comm., L 296, 21.11.1996, p. 55

[15] Council European Union, Directive 1999/30/EC of 22 April 1999 relating to limit values for sulphur dioxide, nitrogen dioxide and oxides of nitrogen, particulate matter and lead in ambient air, Off. Jour. Europ. Comm., L 163, 29.6.1999, p.41

[16] Directive 2000/69/EC of the European Parliament and of the Council of 16 November 2000 relating to limit values for benzene and carbon monoxide in ambient air, Off. Jour. Europ. Comm., L 313, 13.12.2000, p.12

[17] Directive 2002/3/EC of the European Parliament and of the Council of 12 February 2002 relating to ozone in ambient air, Off. Jour. Europ. Comm., L 67, 09.03.2002, p. 14

[18] Directive 2004/107/EC of the European Parliament and of the Council of 15 December 2004 relating to arsenic, cadmium, mercury, nickel and polycyclic aromatic hydrocarbons in ambient air, Off. Jour. Europ. Comm., L 23, 26.01.2005, p. 3-16

[19] Directive 2008/50/EC of the European Parliament and of the Council of 21 May 2008 on ambient air quality and cleaner air for Europe, Off. Jour. Europ. Comm., L152, 11.06.2008, p. 1

[20] Council Decision 97/101/EC of 27 January 1997 establishing a reciprocal exchange of information and data from networks and individual stations measuring ambient air pollution within the Member States, Off. Jour. Europ. Comm., L 35, 5.02.1997, p. 14-22

[21] Commission Decision 2001/752/EC of 17 October 2001 amending the Annexes to Council Decision 97/101/EC establishing a reciprocal exchange of information and data from networks and individual stations measuring ambient air pollution within the Member States, Off. Jour. Europ. Comm., L 282, 26.10.2001, p. 69-76

[22] Directive 2008/1/EC of the European Parliament and of the Council of 15 January 2008 concerning Integrated Pollution Prevention and Control, Off. Jour. Europ. Comm., L 24, 29.01.2008, p.8

[23] Council European Union, Directive 96/61/EC of 24 September 1996 concerning integrated pollution prevention and control, Off. Jour. Europ. Comm., L 257, 10.10.1996, p.26

[24] Commission Decision 2000/479/EC of 17 July 2000 on the implementation of a European pollutant emission register (EPER) according to Article 15 of 
Council Directive 96/61/EC concerning integrated pollution prevention and control (IPPC), Off. Jour. Europ. Comm., L 192, 28.07.2000, p.36

[25] Directive 2001/80/EC of the European Parliament and of the Council of 23 October 2001 on the limitation of emissions of certain pollutants into the air from large combustion plants, Off. Jour. Europ. Comm., L 39, 27.11.2001, p. 1

[26] Directive 2000/76/EC of the European Parliament and of the Council of 4 December 2000 on the incineration of waste, Off. Jour. Europ. Comm. L $332,28.12 .2000$ p. 91

[27] Council Directive 1999/13/EC of 11 March 1999 on the limitation of emissions of volatile organic compounds due to the use of organic solvents in certain activities and installations, Off. Jour. Europ. Comm. L 85, 29.03.1999 p. 1

[28] Directive 2004/42/CE of the European Parliament and of the Council of 21 April 2004 on the limitation of emissions of volatile organic compounds due to the use of organic solvents in certain paints and varnishes and vehicle refinishing products and amending Directive 1999/13/EC, Off. Jour. Europ. Comm. L 143, 30.4.2004, p. 87

[29] Council Directive 1999/32/EC of 26 April 1999 relating to a reduction in the sulphur content of certain liquid fuels and amending Directive 93/12/EEC, Off. Jour. Europ. Comm. L 121, 11.05.1999 p. 13

[30] Directive 2005/33/EC of the European Parliament and of the Council of 6 July 2005, amending Directive 1999/32/EC, Off. Jour. Europ. Comm. L 191, 22.07.2005 p. 59

[31] Directive 98/70/EC of the European Parliament and of the Council of 13 October 1998 relating to the quality of petrol and diesel fuels and amending Council Directive 93/12/EEC, Off. Jour. Europ. Comm. L 350, 28.12.1998 p. 58

[32] Commission Directive 2000/71/EC of 7 November 2000 to adapt the measuring methods as laid down in Annexes I, II, III and IV to Directive 98/70/EC of the European Parliament and of the Council to technical progress as foreseen in Article 10 of that Directive, Off. Jour. Europ. Comm. L 287, 14.11.2000 p. 46

[33] Directive 2003/17/EC of the European Parliament and of the Council of 3 March 2003 amending Directive 98/70/EC relating to the quality of petrol and diesel fuels, Off. Jour. Europ. Comm. L 76, 22.03.2003 p. 10

[34] Directive 98/69/EC of the European Parliament and of the Council of 13 October 1998 relating to measures to be taken against air pollution by emissions from motor vehicles and amending Council Directive 70/220/EEC, Off. Jour. Europ. Comm. L 350, 28.12.1998 p. 1

[35] Directive 2005/55/EC of the European Parliament and of the Council of 28 September 2005 on the approximation of the laws of the Member States relating to the measures to be taken against the emission of gaseous and particulate pollutants from compression-ignition engines for use in vehicles, and the emission of gaseous pollutants from positive-ignition 
engines fuelled with natural gas or liquefied petroleum gas for use in vehicles, Off. Jour. Europ. Comm. L 275, 20.10.2005 p. 1

[36] Commission Directive 2005/78/EC of 14 November 2005 implementing Directive 2005/55/EC of the European Parliament and of the Council on the approximation of the laws of the Member States relating to the measures to be taken against the emission of gaseous and particulate pollutants from compression-ignition engines for use in vehicles, and the emission of gaseous pollutants from positive ignition engines fuelled with natural gas or liquefied petroleum gas for use in vehicles and amending Annexes I, II, III, IV and VI thereto, Off. Jour. Europ. Comm. L 313, 29.11.2005 p. 1 